\title{
Assessment big data in Nigeria: Identification, generation and processing in the opinion of the experts
}

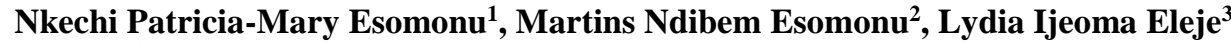 \\ ${ }^{1,3}$ Department of Educational Foundations, Nnamdi Azikiwe University, Nigeria \\ ${ }^{2}$ Department of Electrical Electronics Technology Education, Federal College of Education (Technical) Umunze, Nigeria
}

\begin{abstract}
Article Info
Article history:

Received Sep 26, 2019

Revised Feb 26, 2020

Accepted Apr 28, 2020

\section{Keywords:}

Big data

Generation

Identification

Learning

Processing

ABSTRACT

As a result of increasing complexity of assessing all aspects of human behaviours, a lot of data are generated on individual learner and from teachers and the system. What qualifies as big data in assessment in Nigeria? This research identifies the sources of assessment big data in Nigeria, investigates how the big data are generated and processed, and identifies the problems of generating and processing assessment big data in Nigeria. Through purposive sampling technique forty-five experts in education assessment and research were selected. The instruments for data collection were interview and documents. The data collected were analysed using descriptive statistics to answer the five research questions that guided the research. The results of the investigation showed that the internal and external examinations and assessments from secondary schools, and course work results in universities were identified by more than $95.5 \%$ of the experts interviewed as the major sources of assessment data in Nigeria. The major problem in generating and processing assessment big data from the experts' opinions is low awareness on the need/advantages of assessment big data with the highest mean rating $(4.29 \pm 0.76)$. Many data are not analysed and a lot of information are lost. Recommendation was made amongst others on the need for the stakeholders to create awareness on the importance of big data in the modern education system to improve learner's performance.
\end{abstract}

This is an open access article under the CC BY-SA license.

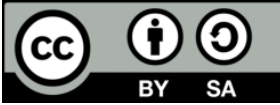

\footnotetext{
Corresponding Author:

Lydia Ijeoma Eleje,

Department of Educational Foundations,

Faculty of Education,

Nnamdi Azikiwe University,

Awka Anambra State, Nigeria.

Email: li.eleje@unizik.edu.ng
}

\section{INTRODUCTION}

The issue of big data consequently resulted in application of modern technology to capture the array of information that is generated. Big data refer to the gargantuan bulk of data that cannot be dealt with by traditional data-handling techniques [1,2]. Big data encompass the use of technologies to capture process, analyse, and visualize potentially large datasets in a reasonable timeframe. Big data have three characteristics namely; volume, velocity and variety. Volume refers to the large quantities of data that are generated continuously through e-commerce and social networking websites, online teaching, learning and assessment [3]. The challenge of storing these data will be better done by new technology. Velocity dimension of big data describes the speed at which the large quanta of data are being generated. That is, both the rate at which data arrive and the time in which it must be acted upon. For instance, Facebook generates 
2.7 billion like action per day and 300 million photos amongst others, amounting to 2.5 million pieces of content in each day; while Google now process over 1.2 trillion searches per year word title [1, 4]. Variety usually means heterogeneity of data types, representation, and semantic interpretation. Variety of data are generated through many instruments and techniques such as documents, databases, excel tables, pictures, videos in hundreds of formats, social networking sites, sensors and satiates. Big data are closely associated to educational data mining, structured and unstructured data, and supervised and unsupervised learning. Educational data mining according to Nithya et al and Eleje et al refers to techniques, tools and research designed to automatically extract meaning from large repositories of data generated by or related to people's earning activities (learning assessment) in education setting [5,6]. The quest for learners to achieve the $21^{\text {st }}$ century skills created the impetus to the use of innovative teaching, learning and assessment strategies $[4,7,8]$. In the context of education, big data are generated from assessment. Assessment big data refers to learner data that is deep and broad $[9,10]$. This broad data comes from internal examinations and assessment; e-feedback of students' evaluation; on-line end of term results of student; teacher-made formative test scores; and performance test indicator from classroom assessment technique. For students' assessment to be easily accessed and continually monitored, on-line learning platform is therefore required. Through continuous assessment of student learning and the subsequent feedback in form of assessment results, assessment big data are generated in quantum [11, 12].

Despite the quantum data generated from assessment in education, assessment big data are faced with various challenges which includes student's privacy, difficulty in accessing required data, accuracy of data and timeliness of feedback, insufficient number of trained personnel to use big data, integration of structured and unstructured data from different sources, and cost of learning analytics software [13-15]. In Nigeria, the generated big data from assessment are not correlated to provide feedback for enhancing students' learning and performance [16-18]. Students' responses in assignments and examinations mainly serve as a measurement of students' performances in an area rather than to aid in data-based decision making in Nigeria [19]. One may wonder whether educators, policy makers, government agency, etc., are aware of the sources, types, proportions, uses, and future of assessment big data in Nigeria. Research on identification, generation and uses of assessment big data in education is a recent development that needs more work. It is scarce, if not completely unavailable. Thus, this study that seeks to find out assessment big data in Nigeria its identification, generation and processing in the opinions of the experts will contribute to the literature on assessment big data.

This study is delimited to finding out the opinion of assessment experts on sources of assessment big data; types and proportions of assessment big data; problems in generating and processing assessment big data; and the future of assessment big data in Nigeria.

\section{RESEARCH METHOD}

The study employed descriptive survey design. Survey research design is one in which a group of items or people are studied by collecting and analyzing data from only a few people or items considered to be representative of the entire group [20,21]. This design is considered appropriate for the present study as it sought to find out assessment big data in Nigeria its identification, generation and processing in the opinions of the experts. The population of the study consisted of experts in educational measurement and evaluation, education research and statistics. Purposive sampling technique was used to select forty-five (45) experts from 10 universities (7 Federal; 3 State) in five geo-political zones in Nigeria. These 45 experts consisted of 20 males and 25 females. A semi-structured interview schedule and documents were used to collect the necessary data. The experts were asked to provide answers to the questions posed to them and to assign rates to the described answers in a scale of 1-5 based on its relevance. The higher the number, the more relevance/importance attached to it. The quantitative data were analysed using frequency, percentage, mean and standard deviation, while themes in the qualitative data were identified and used to support quantitative data gathered. The results were described and presented.

\section{RESULTS AND DISCUSSION}

\subsection{Research question 1: What are the sources of assessment big data in Nigeria?}

Table 1 presents sources of assessment big data in secondary schools as identified by the experts interviewed. Three sources of assessment big data in secondary schools were mentioned by more than half $(\geq 23)$ of the experts interviewed. In Table 2, the identified sources of assessment big data in universities according to experts' opinion are presented. Four out of six sources identified were mentioned by more than half $(\geq 23)$ of the experts interviewed. Course work results were mentioned by all the interviewee. 
Table 1. Sources of assessment big data in secondary schools from experts' opinions

\begin{tabular}{cccc}
\hline S/N & Description & Frequency & Percentage \\
\hline 1 & Internal and External Examinations and Assessments & 43 & $95.5 \%$ \\
2 & e-feedback of students evaluation & 15 & $33.3 \%$ \\
3 & On-line end of term results of students & 40 & $88.8 \%$ \\
4 & Teacher-made formative test scores & 35 & $77.7 \%$ \\
5 & Performance test indicator from classroom assessment techniques & 20 & $44.4 \%$ \\
\hline \multicolumn{2}{l}{ Source: Authors }
\end{tabular}

Table 2. Sources of assessment big data in the universities from experts' opinions

\begin{tabular}{cccc}
\hline S/N & Description & Frequency & Percentage \\
\hline 1 & Application forms & 25 & $55.5 \%$ \\
2 & Qualifying examinations by some universities & 15 & $33.3 \%$ \\
3 & Registration data from admitted students & 40 & $88.8 \%$ \\
4 & Course work results & 45 & $100 \%$ \\
5 & Seminars & 20 & $44.4 \%$ \\
6 & Students' Projects & 35 & $77.7 \%$ \\
\hline Source: Authors & &
\end{tabular}

\subsection{Research question 2: What are the different types and proportions of assessment data generated in Nigeria?}

Different types and proportions of assessment data generated in Nigeria as seen in Table 3 comes from education sector which includes the examination bodies like West African Examination Council (WAEC) and Joint Admission and Matriculation Board (JAMB), and different levels of education systemprimary, secondary and tertiary. The structured data generated are easily processed. Some of the assessment big data in Nigeria generated by WAEC and JAMB are presented in Table 4 and Table 5.

In ten years WAEC generated about 138,900,564 scores as data from subjects registered by students. In each year, WAEC candidates must register 9 subjects each, from which exam scores of their performance are generated. Also, JAMB in ten years generated about 138,245,696 data as exam scores from the four subjects registered by each student. These constitutes part of assessment big data generated in Nigeria.

Table 3. Different types and proportions of assessment data generated in Nigeria

\begin{tabular}{ccccc}
\hline Sector & Type of data & Frequency & Variables covered & Size \\
\hline Primary Schools & Unstructured & Intermittent & Entrance examination results, continuous assessment scores, end of & Thousands \\
Post primary & Unstructured & Intermittent & Entrance examination results, continuous assessment scores, end of & Thousands \\
Schools & term results, mock examination scores & Senior secondary certificate examination results \\
WAEC & Structured & Annually & Unified tertiary matriculation (UTM) examination results & Millions \\
JAMB & Structured & Annually & Post UTME screening test scores, continuous assessment scores, & Millions \\
Tertiary & Structured/ & Intermittent & examination results, students' project assessment scores & \\
Institutions & Unstructured & &
\end{tabular}

Table 4. Data generated by WAEC from students' registration and examination scores

\begin{tabular}{cccc}
\hline S/N & Year & No. of students that participated in the exam & No. of scores generated from 9 subjects \\
\hline 1. & 2009 & $1,373,009$ & $12,357,081$ \\
2. & 2010 & $1,351,557$ & $12,164,013$ \\
3. & 2011 & $1,540,250$ & $13,862,250$ \\
4. & 2012 & $1,675,224$ & $15,077,016$ \\
5. & 2013 & $1,543,683$ & $13,893,147$ \\
6. & 2014 & $1,692,435$ & $15,231,915$ \\
7. & 2015 & $1,593,442$ & $14,340,978$ \\
8. & 2016 & $1,544,234$ & $13,898,106$ \\
9. & 2017 & $1,559,162$ & $14,043,600$ \\
10. & 2018 & $1,560,400$ & $14,043,600$ \\
Total & $15,433,396$ & $138,900,564$ \\
\multicolumn{3}{l}{ Source: } & \multicolumn{2}{l}{ WAEC (In ten years WAEC generated about 138,900,564 scores in addition to the bio data of the students) }
\end{tabular}


Table 5. Data generated by JAMB on unified tertiary matriculation examination

\begin{tabular}{cccc}
\hline S/N & Year & No. of students that participated in the exam & No. of scores generated from 9 subjects \\
\hline 1. & 2009 & $1,182,381$ & $4,729,524$ \\
2. & 2010 & $1,513,940$ & $6,055,760$ \\
3. & 2011 & $1,493,604$ & $5,974,416$ \\
4. & 2012 & $1,503,889$ & $6,015,556$ \\
5. & 2013 & $1,629,102$ & $6,516,408$ \\
6. & 2014 & $1,600,000$ & $6,400,000$ \\
7. & 2015 & $1,400,000$ & $5,600,000$ \\
8. & 2016 & $1,589,175$ & $6,356,700$ \\
9. & 2017 & $1,736,571$ & $6,946,284$ \\
10. & 2018 & $1,662,762$ & $6,651,048$ \\
Total & $15,311,424$ & $61,245,696$ \\
\multicolumn{3}{l}{ Source: JAMB (In ten years JAMB genetared about 61,245,696 scores in addition to students bio data) }
\end{tabular}

\subsection{Research question 3: How are big data in assessment generated in Nigeria?}

Big data in Nigeria are generated through various activities of the students, teachers in the school system, lecturers in tertiary institutions and education environment. During admission processes, students provide their bio data by filling in forms in hard copies. Biometrics of students are also captured online. At the Basic Education and Secondary School levels, students do midterm tests, continuous assessment and termly examinations. This is done three times a year. In Nigeria, these are predominantly carried out using paper and pencil test. But the termly examination results are published online. At the end of Senior Secondary in Nigeria, students seat for external examinations conducted by different examination bodies. Some of them are West African Examination Council (WAEC), National Examination Council (NECO), National Business and Technical Education Board (NABTEB). For the examinations conducted by theses bodies, the candidates register online, take the paper and pencil examination but their results scores are captured online from which big assessment data are generated.

Accordingly, institutions generate big data through the conduct of computer-based examination $[22,23]$. The Joint Admission and Matriculation Board (JAMB) which is the Nigerian entrance examination board for tertiary level, register candidates online, do computer-based examination and results captured online. Most universities in Nigeria also conduct Post Unified Tertiary Matriculation Examination as a further screening for candidates seeking admission into the universities. In many of the universities, the candidates register online, they do computer-based examination and the results are captured and published online. Candidates who are admitted supply their bio data online during the first and subsequent registrations. There are physical clearance processes where biometrics is applied. In line with this Aworanti in his studies noted these universities that are implementing the e-examination in screening and assessment of their students [24, 25]. However, most of the academic or learning assessment of the students is through classroom contacts, use paper and pencil in in-course assessments and examinations are done. Students present seminars, carry out and defend their projects, theses and dissertations. But, many of the summative evaluation data are generated and published online. Administrative staff teachers and lecturers do a lot of documentation during employment. There are annual appraisals of staff in education institutions and a lot of data are generated.

\subsection{Research question 4: How is assessment big data used in Nigeria?}

In Table 6, the identified uses of assessment big data in Nigeria according to experts' opinions are presented. Eight out of ten uses identified were mentioned by more than half $(\geq 23)$ of the experts interviewed.

Table 6. Uses of assessment big data in Nigeria from experts' opinions

\begin{tabular}{cccc}
\hline S/N & In Nigeria assessment big data is used for... & Frequency & Percentage \\
\hline 1 & admission purposes & 30 & $66.7 \%$ \\
2 & Promotions & 25 & $55.6 \%$ \\
3 & monitoring students' learning & 40 & $88.8 \%$ \\
4 & students certification & 45 & $100 \%$ \\
5 & curriculum modifications & 20 & $44.4 \%$ \\
6 & earning awards & 35 & $77.7 \%$ \\
7 & assignment of grades & 43 & $95.6 \%$ \\
8 & school comparison & 35 & $77.7 \%$ \\
9 & supervision in adjusting teaching and learning & 30 & $66.7 \%$ \\
10 & government decision making & 21 & $46.7 \%$ \\
\hline Source: Authors &
\end{tabular}

Int. J. Eval. \& Res. Educ. Vol. 9, No. 2, June 2020: 345 - 351 


\subsection{Research question 5: How are big data in assessment processed?}

Currently in Nigeria, processing of assessment data - data collection, entering, analysing and reporting of the findings - are done online and also published online. Examination bodies like WAEC, NECO, NABTEB and JAMB do online registration of their candidates. They process and publish their results online. Many universities use biometrics in handling the students' biological data. Some institutions do engage the services of companies or firms in processing their assessment data. However, in calculating and reporting of assessment big data in Nigeria simple descriptive statistics are mainly used. Currently, lack of substantial data base is a problem. The existing big data are mostly compressed, inferential statistics are mostly used to calculate confidence interval and estimators are used to handle population parameters. With these, many data are not analysed and a lot of information are lost.

\subsection{Research question 6: What are the problems in generating and processing assessment big data in Nigeria?}

Table 7 shows the mean and standard deviation of experts' opinions ratings on problems in generating and processing assessment big data in Nigeria. The mean ratings ranged from 3.36 to 4.29 and the standard deviation ranged from 0.76 to 0.90 . The major problem in generating and processing assessment big data from the experts' opinion is low awareness on the need/advantages of assessment big data with the highest mean rating (4.29 \pm 0.76$)$, followed by security issues in contracting data analyst (4.02 \pm 0.89$)$, low level of infrastructural development and technical knowhow (3.89 \pm 0.89$)$, etc., while lack of trained ICT officers had the least mean rating $(3.36 \pm 0.83)$.

Themes emerging from the qualitative data collected pointed to the fact that huge quantum of data captured are not processed and used in making critical decisions about student's behaviour, academic achievement and welfare. For instance, student's background information are not processed and used to see the extent the student's attitude are linked to the achievement and how student's affective behaviour can be enhanced. There is also the challenge of creating awareness on the need to build database. There is need to educate people on the advantages of big data. Other challenges include lack of electric power, poor access to internet, lack of personnel and experts for programming and modelling, lack of awareness among experts and professionals.

Table 7. Experts' opinions ratings on problems in generating and processing assessment big data in Nigeria

\begin{tabular}{ccccc}
\hline S/N & Description & $\mathrm{N}$ & Mean Rates & SD \\
\hline 1 & Low awareness on the need/advantages of assessment big data & 45 & 4.29 & 0.76 \\
2 & Lack of competent data analysts & 45 & 3.71 & 0.90 \\
3 & Lack of trained ICT officers & 45 & 3.36 & 0.83 \\
4 & Security issues in contracting data analyst & 45 & 4.02 & 0.89 \\
5 & Lack of ICT software & 45 & 3.80 & 0.87 \\
6 & Low level of infrastructural development and technical knowhow & 45 & 3.89 & 0.89 \\
7 & Lack of substantial data base & 45 & 3.35 & 0.83 \\
\hline Source: Authors & & & &
\end{tabular}

\subsection{Research question 7: What is the future of assessment big data in Nigeria?}

Table 8 shows the mean and standard deviation of experts' opinions ratings on their perceived future of assessment big data in Nigeria. The mean ratings ranged from 2.92 to 4.30 and the standard deviation ranged from 0.63 to 0.90 . The major areas of prospect for assessment big data according to the experts' opinions ratings is training of ICT officers to better handle assessment big data with the highest mean rating (4.30 \pm 0.90$)$, followed by institutions with big data assessment framework in their blueprint (3.98 \pm 0.89$)$, Schools committed to developing sophisticated ICT infrastructure (3.80 \pm 0.89$)$, etc., while government to put in place necessary infrastructure for generating and analysing complex data had the least mean rating $(2.92 \pm 0.63)$. The standard deviations reveal that the experts were unanimous in their perceptions.

Table 8 . The future of assessment big data in Nigeria as rated by the experts

\begin{tabular}{|c|c|c|c|c|}
\hline $\mathrm{S} / \mathrm{N}$ & Areas of prospect for assessment big data & $\mathrm{N}$ & Mean Rates & SD \\
\hline 1 & An increase in power and ability to log fine students' learning data & 45 & 3.59 & 0.76 \\
\hline 2 & Training of ICT officers to better handle assessment big data & 45 & 4.30 & 0.90 \\
\hline 3 & Critical decisions based on results of assessment data analysis & 45 & 3.10 & 0.83 \\
\hline 4 & Schools committed to developing sophisticated ICT infrastructure & 45 & 3.80 & 0.89 \\
\hline 5 & Assessment data to inform policy & 45 & 3.30 & 0.87 \\
\hline 6 & Institutions with big data assessment framework in their blueprint & 45 & 3.98 & 0.89 \\
\hline 7 & Government to put in place necessary infrastructure for generating and analysing complex data & 45 & 2.92 & 0.63 \\
\hline
\end{tabular}

Assessment big data in Nigeria: Identification, generation and ... (Nkechi Patricia-Mary Esomonu) 
Within the education system, vast array of assessment data are gathered from students information systems, library usage, attendance data, participation in online fora, eye movement, facial recognition data to the widely-used data source, students interactions with the virtual learning environment. In Table 1 and Table 2, the various sources of assessment big data as identified by the experts interviewed were presented, and Table 3 to Table 5 portrayed different types and proportions/volume of assessment data generated in Nigeria. These data need to be technically utilized for education sector to benefit from amassing of big data. In Nigeria, the volumes of data have not been effectively tapped as to have a full benefit of big data. The scores generated were mostly used for selection, promotion and placement as observed in Table 6 . Researches on modelling for predicting future behaviour of students, and improvement in achievement which are the hallmark of building database are grossly neglected [24, 26, 27]. The experts are not doing the needful because what people do not know, they cannot measure, what they do not measure, they cannot judge.

As observed in Table 7, low awareness on the need/advantages of assessment big data, security issues in contracting data analyst and low level of infrastructural development and technical knowhow were identified as the major problem in generating and processing assessment big data. This is in agreement with potential challenges in generating and analysing big data stipulated by Hammer et al and Macfadyen et al in generating and analysing big data [28, 29]. It is also in line with Rajagopalan, and Cope and Kalantzis who proposes that for an easy generating and processing of assessment big data, effective institutional technology infrastructure is required $[30,31]$.

In Nigeria, it is hoped that there will be an increase in the computer-based learning environment which will increase power and ability to log fine-grained data about students' learning. With the training and retraining of Information and Communication Technology (ICT) officers, big data in education will be better handled. The full benefit of big data in the system will begin to manifest when critical decisions are taken based on results of data analysis and when the assessment big data inform policy. There should be strategic plans for collecting data, record creating in all education activities. There should be education history for pupils and students. This will help in designing models for explaining learners' behaviour, attitude, and achievement and so on. The necessary infrastructure for generating and analysing complex data needs to be put in place.

\section{CONCLUSION}

The researchers from the findings of this study conclude that there exists low awareness on the advantages of assessment big data from the part of policy makers in Nigeria. The amassed assessment big data mainly ends up in students' placement and certification. With a developed database system, easy generating, processing and accessing of assessment big data may be established. Then the full benefit of assessment big data will manifest as critical decisions taken are based on results of data analysis.

There is need for the stakeholders to create awareness on the importance of big data in the modern education system to improve learners' performance. There should be a strategic plan in building our database to gain the advantages of big data. The infrastructural and technological materials necessary for big data operation should be put in place. There is need to improve the internet connectivity, and electric power supply in institutions. Training and retraining are imperative to make the operators and staff of education enterprise computer and internet compliant and efficient. Biometric data capturing need to be expanded in handling learners' issues in admission, registration and predicting learners' future behaviour and performance.

\section{REFERENCES}

[1] S. Mukherjee and R. Show, "Big data- Concepts, Applications, challenges and Future Scope," International Journal of Advanced Research in Computer and Communication Engineering, vol. 5, no. 2, pp. 66- 74, 2016.

[2] M. Aktaruzzaman, M. R. H. Shamim, and C. K. Clement, "Trends and issues to integrate ICT in teaching learning for the future world of education," International Journal of Engineering \& Technology IJET-IJENS, vol. 11, no. 3, pp. 114-119, 2011.

[3] M.V. Adegbija, M.A. Fakomogbon, and F.O. Daramola, "The new technologies and the conduct of e-examinations: A case study of National Open University of Nigeria," British Journal of Science, vol. 3, no. 59, 2012.

[4] UNESCO Institute for Statistics (UIS), "International Standard Classification of Education: ISCED 2011," Montreal: UNESCO Institute for Statistics, 2012. [Online]. Available: http://www.uis.unesco.org/Education/Documents/isced-2011-en.pdf

[5] P. Nithya, B. Umamaheswari, and A. Umaderi, "A survey on educational data mining in field of education," International Journal of Advance Research in Computer Engineering and Technology (IJARCET), vol. 5, no. 1, pp. 69-78, 2016. 
[6] L.I. Eleje, N.P.M. Esomonu, and F.N. Ufearo, "Trends in information and communication technology and learning assessment: the application and implication," International Educational Applied Research Journal (IEARJ), vol. 03 , no. $11,2019$.

[7] L. F. Gul, "The changing trends in education," ICT, vol. 2, no. 1 2015. [Online]. Available: https://www.frontiersin.org/articles/10.3389/fict.2015.00001/full

[8] N. Gu, L. F. Gül, A. Williams, and W. Nakapan, "Conquering new worlds," Proceedings of the 14th International Conference on Computer Aided Architectural Design Research in Asia/Yunlin (Taiwan), Between Man and Machine? Integration, Intuition, Intelligence 2009, Taiwan, pp. 153-164, 2009.

[9] United Nations Educational, Scientific and Cultural Organization, The data revolution in education. Canada: Succursale Centre-Ville Montreal, Quebec, 2017.

[10] C. Thille, E. Schneider, R. F. Kizileec, C. Piech, S. A. Halawa, and D. K. Greene, "The future of data-enriched assessment," In J. Brown (Ed.), Research and Practice in Assessment. Special Issue: Big data and learning analytics, vol. 9, pp. 5-14, 2014.

[11] J. Muskin, "The data revolution and education post-2015: Considering the promise and the risks," 2015. [Online]. Available: https://www.brookings.edu/blog/education-plus-development/2015/03/31/the-data-revolution-andeducation-post-2015-considering-the-promise-and-the-risks/

[12] J. Cresswell, U. Schwantner, and C. Waters, A review of international large-scale assessments in education: assessing component skills and collecting contextual data. Paris: Organisation for Economic Co-operation and Development, 2015.

[13] S. Anirban, "Big data analytics in the education sector: Needs, opportunities and challenges," International Journal of Research in Computer and Communication Technology, vol. 3, no. 11, pp. 12-20, 2014.

[14] A. G. Picciano, "Big data and learning analytics in blended learning environments: Benefits and concerns," Interactive Journal of Artificial Intelligence and Interactive Multimedia, vol. 2, no. 7, pp. 35-43, 2014.

[15] K. J. Ihechu and N. Ugwuoji, "Evaluation of the application of ICT in continuous assessment by academic staff of universities in Abia State, Nigeria," International Journal of Scientific Research in Education, vol. 10, no. 1, pp. 102-111, 2017.

[16] K. Salisu, "E-government adoption and framework for big data analytics in Nigeria," National Information Technology Development Aagency (NITDA). 2015

[17] C. A. Ugodulunwa and C. M. Anikweze, "Big data and assessment for learning in Nigeria universities: Prospects and challenges," 2019.

[18] UNICEF, "Monitoring Education Participation: Framework for Monitoring Children and Adolescents Who Are out of School or at Risk of Dropping out," Geneva: UNICEF, 2016.

[19] K. Schildkamp, M. Ehren, and M. K. Lai, "Editorial article for the special issue on data-based decision making around the world: From policy to practice to results," School Effectiveness and School Improvement, vol. 23, no. 2, pp. 123-131, 2012.

[20] B. G. Nworgu, Educational research: Basic issues and methodology, (2nd ed). Enugu: University trust publishers, 2015.

[21] C. R. Kothari and G. Garg, Research methodology: Methods and techniques. Delhi India: New Age International (P) Ltd, Publishers, 2014.

[22] D.A. Dotimi, and J-T. Hamilton-Ekeke, "Information and Communication Technology (ICT) - E-Learning in Nigerian Tertiary Institutions," The Librarian and Information Manager, vol. 6, no. 1, pp. 44-59, 2013.

[23] J-T. Hamilton-Ekeke and C. E. Mbachu, "The Place of Information, Communication and Technology (ICT) in Teaching and Learning in Nigerian Tertiary Institutions," American Journal of Educational Research, vol. 3, no. 3, pp. 340-347, 2015.

[24] O. A. Aworanti, "Transforming public examining system through the application of latent trait models," 2nd Institute of Education international conference, University of Ibadan, Ibadan, Nigeria, 2013.

[25] O. A. Aworanti, "Information and communications technology (ICT) in Nigeria educational assessment system emerging challenges," Universal Journal of Educational Research, vol. 4, no. 6, pp. 1351-1356, 2016.

[26] C. M. Beukes-Amiss and E. R. T. Chiware, "The impact of diffusion of ICT"es into educational practices, how good or how bad? A review of the Namibia situation," 2006.

[27] C. Campbell and B. Levin, "Using data to support educational improvement," Educational Assessment, Evaluation and Accountability, vol. 21, pp. 47-65, 2009.

[28] C. L. Hammer, D. C. Kostroch, G. Quird, and Sta Internal Group, "Big data: Potential, challenges and statistical implications," 2017.

[29] L. P. Macfadyen, S. Dawson, A. Pardo, and D. Gasevi, "Embracing big data in complex educational systems: The learning analytics imperative and the policy change," Research and Practice in Assessment, vol. 9, no. 2, pp. 17-28, 2014.

[30] M. R. Rajagopalan, NRC-FOSS, "Big Data Framework for National e-Governance Plan by Eleventh International Conference on ICT and Knowledge Engineering," Centre for Development of Advanced Computing Chennai, India, 2013.

[31] B. Cope and M. Kalantzis, "Big data comes to school: Implications for learning, assessment, and research," 2016. 